\title{
NN Combinations in Greek
}

\author{
Zoe Gavriilidou \\ Democritus University of Thrace \\ zoegab@otenet.gr
}

\begin{abstract}
In this paper, multiword NN combinations in Greek are explored within the framework of construction morphology (Booij 2009, 2010a, 2010b). I understand NN combinations as multiword sequences constructed by two inflected words, such as: arxitéktonas-arxeolóyos 'architect-archeologist'; taksioi-astrapí lit. 'trip-lightning', thus 'very fast and sudden trip'; sáltsa manitárja lit. 'sauce mushrooms', thus 'mushroom sauce'. I use the classification of Gavriilidou (1997) in order to account for possible different subtypes of $\mathrm{NN}$ combinations. I claim that all three types of NN combinations (coordinate, attributive and complementation NN combinations) are visible to syntactic operations, they exhibit, however, various degrees of tightness which are due to whether they exhibit a naming function or not.
\end{abstract}

\section{Keywords}

construction morphology; compounding; attribution; complementation; coordination; constructional idiom; hierarchical lexicon

\section{Definition and Main Claims}

There are many different NN combinations in Greek as illustrated in (1):

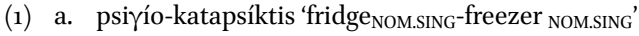

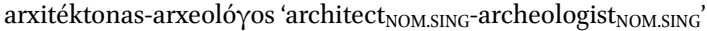

b. taksíסi-astrapí lit. 'trip ${ }_{\mathrm{NOM} . S I N G}$-lightning ${ }_{\mathrm{NOM} . \mathrm{SING}}$ ', thus 'very fast and sudden trip'

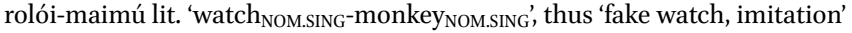

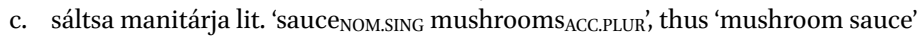

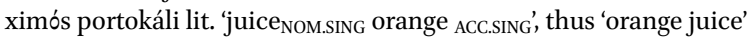

These combinations contain two inflected words. Their constituents, which are often connected by a hyphen, either co-vary in inflection (1a, b) or notas shown in sections 2.3 and $2.4-$ (see example 1c). Some of them are leftheaded $(\mathrm{lb}-\mathrm{c})$ while in others two heads exist (1a). Among them, some are more opaque to syntactic rules, like adjectival or adverbial modification as illustrated

\footnotetext{
*) I would like to thank the anonymous reviewers for their helpful and constructive comments that greatly contributed to improving the paper.
} 
in sections 2.3 and 2.4, while others are more transparent. In this paper, in order to refer to the studied examples, I adopt the terms $N N$ combinations or $N N$ sequences, which will be interchangeably used in the text instead of $N N$ compounds, a term that refers to a morphological class of words (Booij 2010a: 179). ${ }^{1}$

NN combinations like the ones in (1) contrast with Greek morphological compounds such as pandelonófousta lit. 'pants and skirt', vatraxán Эropos 'frogman', and spanakópita 'spinach pie', which are subject to rightward headedness (as it will be shown in detail in 3). There are two main reasons: on the one hand, morphological compounds in Greek are phonological words, displaying only one stress, and on the other, they are built (following Ralli 2007, 2009) on the basis of two structural patterns, [stem stem] or [stem word]. The [stem stem] constructions bear a different inflectional ending and display a different stress position from those of the second constituent, when autonomous; whereas the [stem word] constructions preserve the stress and inflectional ending of the second constituent and thus inherit their gender specification from the second constituent as well (Nespor and Ralli 1996).

The first approach for Greek NN combinations was that of AnastasiadisSymeonidis (1986) who adopted the term multiword appositional compounds

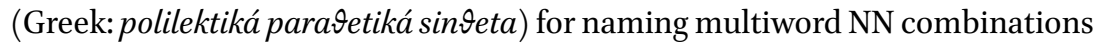
and distinguished - following Barbaud (1971) - between attributive NN compounds (e.g. estiatório-tavérna 'restaurant-tavern'), metaphoric NN compounds

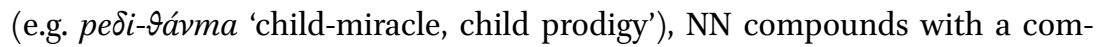

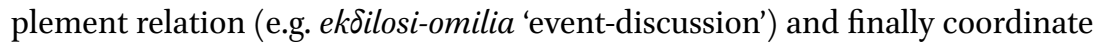

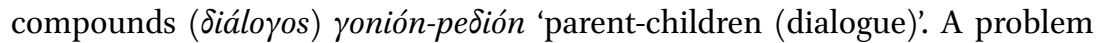
with this classification is that the criteria adopted for establishing it do not allow a clear-cut distinction between metaphoric and attributive compounds. Furthermore, even though the term multiword appositional compounds is used by the author to describe NN constructions, there is no clear evidence for the morphological origin of NN structures which could justify the use of the term compound. Gavriilidou (1997) analyzed the same structures in Greek by using the framework of lexicon-grammar (Gross 1986) and preferred the term $N N$ sequences, given that NN do not share all the properties of typical compounds. Based on syntactic criteria she distinguished between coordinate NN combinations (e.g. psíío-katapsíktis 'fridge-freezer'), attributive NN combinations (e.g. pólemos-astrapí lit. 'war-lightning', thus 'Blitzkrieg') and complementation NN combinations (e.g. sáltsa-manitárja lit. 'sauce-mushrooms', thus 'mushroom

1) For a detailed description of the criteria invoked to identify compounds, i.e. morphological objects from syntactic objects see also Gaeta \& Ricca 2009. 
sauce'). In her analysis, differences in the syntactic properties and the morphological autonomy of the three subtypes of NN combinations were accounted for as a result of a different degree of frozenness (Gross 1988) of each NN combination. However, the theoretical framework which was adopted did not allow for a convincing interpretation of that interaction between morphology and syntax. Finally, Ralli $(2005,2007)$ offered an interesting analysis of $\mathrm{NN}$ combinations by claiming that they belong to a special category of multi-word units whose internal structure is not completely invisible to syntax and which seem to gradually acquire the status of morphological objects, i.e., expressions or entities treated in the morphology. However, no clear evidence is provided about the characteristics of the procedure of 'morphologization' of NN combinations. Thus in the previous literature there is considerable information on how NN combinations are constructed while fewer studies have focused on NN combinations' classifications. Moreover none of the previous analyses managed to maintain the boundary between phrasal and morphological constructs and yet do justice to the lexical properties that some subtypes of NN combinations exhibit. In order to contribute to the previous relevant literature, the purpose of this paper is to offer new insight on the behavior of the different classes of NN combinations considering the main findings and ideas presented in recent literature, to account for the phrasal and lexical nature of $\mathrm{NN}$ combinations, and also to model the regularities in their semantic interpretation and formal construction in the light of Construction Morphology.

The questions I tackle in this paper are the following:

1) Are there different subtypes of NN combinations and if yes, which are the characteristics of each subtype?

2) If we are convinced that there are different subtypes of $\mathrm{NN}$ combinations, how are these subtypes accounted for by construction morphology?

3) Does each specific subtype receive syntactic or morphological interpretations?

4) In case we opt for syntactic interpretations, how can we account, on the one hand, for the functional similarities between morphological compounds and NN combinations and, on the other, for the differences in the morphological autonomy of each subtype?

5) In case we opt for morphological interpretations, how can we account for the left-headedness in NN combinations in Greek which is considered to have right-head compounding?

6) How can we account for the fact that some non-heads in $\mathrm{NN}$ combinations are projecting while others are not?

And finally: 
7) How can we account for the specific meaning that certain non-heads acquire when embedded in attributive NN combinations or for the affixlike behavior of some heads also embedded in attributive NN combinations?

To answer to the first question, I adopt the classification of Gavriilidou (1997). I address all the remaining questions in the light of construction morphology (Booij 2009; 2010a; 2010b). I have chosen the construction morphology frame for my analysis of NN combinations given that it can provide theoretically adequate answers to the above-mentioned questions. More specifically, by the use of notions such as 'constructional idioms' (see 4), construction morphology can maintain the boundary between phrasal and morphological constructs, and yet do justice to the lexical properties that some subtypes of NN combinations exhibit. Furthermore, word production schemas can represent at an abstract level the set of relationships between the constituents of the three types of NN combinations, express predictable properties of NN combinations, and indicate how new NN combinations can be coined (Booij 2010: 4). In this paper, I claim that NN combinations belonging to the class of complementation can be characterized "as constructions in terms of syntactic schemas with specific properties" (Booij 2010a: 169), although I agree with Ralli (2007) that coordinate and attributive NN combinations are syntactically created word constructs which demonstrate morphological-like behavior. However, I show that NN combinations with naming function demonstrate a more morphologicallike behavior than NN combinations without naming function. For doing that, I use the notion of construction and I postulate a gradient on which I try to map the three different classes of $\mathrm{NN}$ combinations.

This paper is structured as follows. In Section 2, I present the classification of Gavriilidou (1997) for multiword NN combinations. The focus is on the characteristics of coordinate, attributive, and complementation NN combinations. In Section 3, each class of NN combinations is analyzed within the framework of the constructional theory of compounding. I argue that in Greek the NN pattern corresponds to two different types of construction: a) NN combinations consisting of two nouns in the same case and b) NN combinations consisting of two nouns, the second being an unmarked accusative due to prepositional omission. I agree with Ralli $(2005,2007)$ in that NN combinations are word constructs with an internal structure that is not completely invisible to syntax; these constructs gradually take on the status of morphological entities. I also claim that complementation combinations are sequences which must be seen as phrases with special syntax in which determiners and prepositions are omitted (Booij 2010a). Finally I show that the various degrees of tightness between the constituents of NN combinations are dependent on whether NN combina- 
tions exhibit a naming function or not. By way of conclusion, in Section 4, I summarize my findings.

\section{Subtypes of NN Combinations in Greek}

Let us begin with the first question: Are there different subtypes of NN combinations in Greek, and if yes, what are the characteristics of each subtype? The answer to that question is crucial in order to examine later on how each one of the different subtypes is accounted for by construction morphology. In Gavriilidou (1997), with its classification of NN combinations, I proposed three different subtypes. In what follows, I revise these criteria, I offer a detailed analysis of this classification, and I discuss the properties of each class considering new data presented in recent literature.

\subsection{Criteria for Classification}

One of the most challenging problems, while establishing a classification, is the adoption of the appropriate criteria so that a) each class is unambiguously distinguished from the others of the same level and those of superior levels and b) each item to be classified can be classified in one and only class.

Gavriilidou's (1997) classification was based on syntactic criteria. The first level of analysis takes into account the syntactic relation that holds between the two constituents of the combination NN. By applying the syntactic criterion of permutation (Criterion $\left.\mathrm{A}: \mathrm{N}_{1} \mathrm{~N}_{2}=\mathrm{N}_{2} \mathrm{~N}_{1}\right)(2 \mathrm{a}, \mathrm{b})$ as well as that of the presence of two heads (Criterion B: $\left.\left[\mathrm{NiN}_{2}\right]_{\mathrm{N1} / 2}\right)(2 \mathrm{c}, \mathrm{d})$ two macro-types are distinguished. NN combinations that meet both criteria (or at least Criterion B) fall into the category of coordination while those which do not, give rise to subordinate compounds (2e, f, g, h).

(2) a. arxitéktonas-arxeolóyos vs. arxeolóyos-arxitéktonas

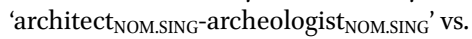
'archeologist ${ }_{\mathrm{NOM} . S I N G}-$ architect $_{\mathrm{NOM.SING}}$ '

b. o kanapés-diváni vs. to diváni-kanapés

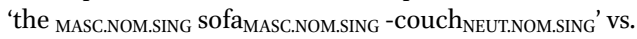
'the NEUT.NOM.SING couch-sofa MASC.NOM.SING'

c. O arxitéktonas-arxeolóyos íne arxitéktonas ké arxeolóyos 'The architect-archeologist is an architect and an archeologist'

d. O kanapés-diváni íne kanapés ké diváni 'The sofa-couch is a sofa and a couch'

e. nómos-plésio vs. * plésio-nómos 'law NOM.SING $^{-}$-frame NOM.SING' $^{\text {vs. '*frame }}$ NOM.SING-law $_{\text {NOM.SING' }}$

f. *O nómos-plésio íne nómos ké plésio "*The law framework is a law and a frame'

g. sáltsa manitárja vs *manitárja sáltsa

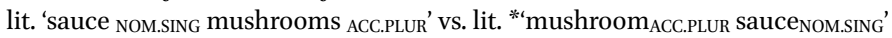


h. *H sáltsa manitárja íne sáltsa ké manitárja

'The mushroom sauce is a sauce and mushrooms'

In coordinate compounds both $\mathrm{N}_{1}$ and $\mathrm{N}_{2}$ share the same status; they both behave as heads (see also Gavriilidou 1997; Ten Hacken 2000; Scalise and Bisetto 2009) at least from a semantic point of view (Bisetto 2010). However, based on the gender agreement of the first constituent with the determiner one could claim that syntactically they are single-headed $(2 b)$ and the head situated at the left determines the morphosyntactic properties of the whole construction. This could probably explain why in some cases the constituent at the left is thought to prevail over the constituent at the right. In subordinate compounds, on the other hand, there is an asymmetrical relation (Arcodia, Grandi and Wälchli 2010) of dependency; the left-situated Ni stands as the semantic and syntactic head, whereas the non-head N2 holds a kind of dependence of N1being either a modifier of $\mathrm{N}_{1}$ or a complement of it. For this reason (2f) and ( $\left.2 \mathrm{~h}\right)$ are infelicitous.

A second classification level is needed in order to account for the syntactic relation that holds between the constituents of subordinate NN combinations. The syntactic test of predication (Criterion C) applied to subordinate constructions allows a further distinction between attributive $\mathrm{NN}$ combinations (3a) which pass Criterion C and share a head-modifier relation and NN combinations which do not pass Criterion C. In ( $3 b)$ the two components share a head-(prepositional) complement relation. Note, however, that the test of predicativity becomes more natural with the adjunction of expressions like san 'like', ópos 'as, like' for Greek.

(3) a. ánӨropos-kliðí: aftós o ánӨropos íne kliðí ...

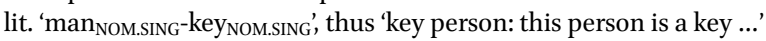

b. sáltsa manitárja: *afti i sáltsa ine manitárja

'sauce ${ }_{\text {NOM.SING }}$ mushrooms ACC.PLUR', thus 'mushroom sauce: *this sauce is mushrooms'

Figure 1 represents the classification of Gavriilidou (1997).

Let us now look systematically at each subclass of NN combinations to see their specific properties. I illustrate my analysis with examples taken from Greek.

\subsection{Coordination}

$\mathrm{N}_{1}$ and $\mathrm{N}_{2}$ in coordinate combinations can be interpreted as being connected with the conjunction 'and'. For instance, in Greek arxitéktonas-arxeoló $\gamma$ os 'architect-archeologist' is both an architect and an archeologist, or psiyio-katapsiktis 'fridge-freezer' is both a fridge and a freezer. According to Gavriilidou (1997), there are four principal characteristics of coordinate combinations. 


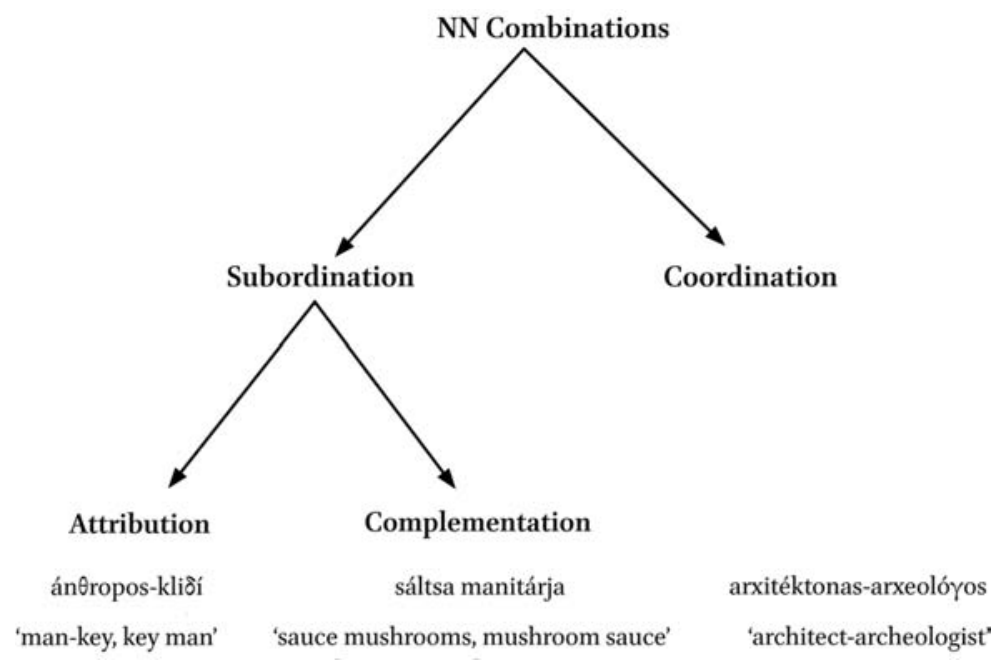

Figure 1. The classification of Gavriilidou 1997

(4) a. Permutation between $\mathrm{N} 1$ and $\mathrm{N}_{2}$

b. Compulsory co-variation in inflection between $\mathrm{N}_{1}$ and $\mathrm{N}_{2}$

c. Possible addition of similar constituents

d. Compulsory use of hyphen

I consider every property in turn.

As mentioned in 2.1, permutation between $\mathrm{N}_{1}$ and $\mathrm{N}_{2}$ is one of the defining criteria of coordinate constructions $(2 \mathrm{a}, \mathrm{b})$. This is also an argument for claiming that coordinate $\mathrm{NN}$ combinations are characterized by two semantic heads. A person who has a degree both in architecture and in archeology is simultaneously an arxitéktonas 'architect' and an arxeolóyos 'archeologist', thus this person is both arxitéktonas-arxeolóyos 'architect-archeologist' and

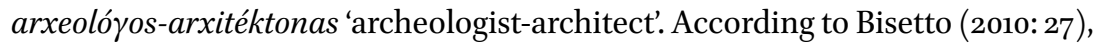
"each 'property' associated with that person can thus stand as the head of the compound." However in some cases permutation is not natural as in (5).

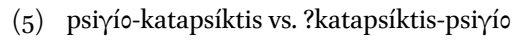

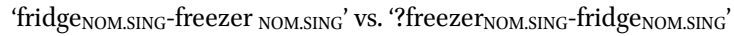

While permutation in general does not affect the meaning of a coordinate combination, the oddity of (5) results from pragmatic reasons which may impose a specific order in coordinate constructions. For instance, it is quite common that for nouns which denote a more commonly used object, or idea, the positive term in a scale of antonyms or what is considered more important in a 
given culture is placed first in such constructions. In some cases prosodic criteria can account for a specific order.

A second characteristic is the compulsory co-variation in inflection, meaning that both constituents should share the same morphosyntactic features of number and case. Thus, pluralization for instance applies to both constituents (Gavriilidou 1997; Scalise and Bisetto 2009) (6a). When the $\mathrm{N}_{1}$ is an animate human, then the second constituent has to agree in gender as well (6b). In Greek, there is compulsory agreement in case as well (6c). Therefore we should conclude that coordinate combinations cannot be interpreted as morphological compounds, given that in morphological compounds the principle of Lexical Integrity forbids syntactic rules such as agreement to apply to complex words. Cross-linguistic parallels in Italian (Gaeta \& Ricca 2009) and French (Fradin 2003) display a convergence as for the syntactic status of coordinate $\mathrm{NN}$ combinations.

(6) a. iӨopií-xoreftés vs. * iӨopií -xoreftís

' actor $_{\text {NOM.PLUR }}$-dancer NOM.PLUR' vs. '* actor $_{\text {NOM.PLUR-dancer }}$ NOM.SING' '

b. énas xoreftís -skinoӨétis vs. *énas xoreftís -skinoӨétria

'a MASC.NOM.SING dancer MASC.NOM.SING -director MASC.NOM.SING' vs.

'*a MASC.NOM.SING dancer MASC.NOM.SING -director FEM.NOM.SING'

c. tú xoreftí -skinoӨéti vs. *tú xoreftí-skinoӨétis

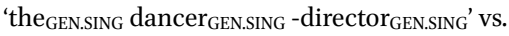

'*the GEN.SING $_{\text {dancer }}$ GEN.SING-director $_{\text {NOM.SING' }}$ '

The third characteristic of coordinate NN combinations is the possible addition of similar constituents (Bisetto 2010). Examples like those in (7) illustrate that constructions of three and more constituents are used to refer to entities which combine multiple characteristics or properties:

(7) iӨopiós-xoreftís-skinoӨétis 'actor ${ }_{N O M . S I N G}-$ dancer $_{\text {NOM.SING }}$-director ${ }_{N O M . S I N G '}$

Finally, let us add that the use of the hyphen between the constituents of coordinate constructions is systematic. This judgment is mirrored by the number of instances of hyphened coordinate compounds in corpus data ${ }^{2}$ which attained a striking $99.9 \%$. The systematic use of the hyphen is probably an indication of the tight relation between the two constituents of coordinate compounds, which further supports Ralli's (2007) claim about coordinate compounds and their gradual move towards being morphological entities.

Coordinate NN combinations are frequently used as names for artists/professions (8a), electric or electronic devices (8b), machines (8c) or locatives (8d).

2) This study was based on the corpus elaborated for the Greek in Gavriilidou (1997) including 2000 NN combinations. 


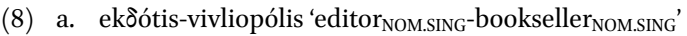

b. psistjéra-tostjéra 'grill NOM.SING $_{\text {- }}$ toaster $_{\text {NOM.SING' }}$

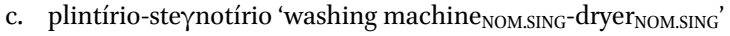

d. artopiío-zaxaroplastío 'bakeryNOM.SING-pastry shop ${ }_{\text {NOM.SING' }}$

Even if they cannot be interpreted as morphological compounds, they seem to exhibit an extremely high morphological autonomy compared to the other two classes of NN combinations: as illustrated in (9a) the insertion test does not apply, consequently the $\mathrm{N}_{2}$ cannot be separated from the $\mathrm{N}_{1}$ by the definite determiner, it cannot accept a modifier ( $9 \mathrm{~b})$, nor can it be split by parenthetical expressions (9c):

(9) a. *o ekסótis o vivliopólis

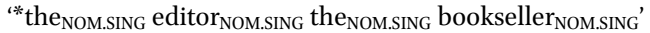

b. * ekdótis enimeroménos vivliopólis

'*editor NOM.SING $_{\text {well informed }}$ NOM.SING $_{\text {bookseller }}$ bOM.SING' $^{\prime}$

c. *o ekdótis -ke ópws ípame- vivliopólis

"*the NOM.SING $_{\text {editor }}$ NOM.SING - and as we said—-bookseller $_{\text {NOM.SING' }}$

Before moving to an examination of the class of attribution, let us say that, interestingly, among NN coordinate combinations, cases like (10a) (below) where each constituent of an $\mathrm{NN}$ combination has a distinct referent are in contrast with cases such as (1ob) which have a unique referent combining the properties of the two constituents (Noailly 1990; Gavriilidou 1997; Fradin 2009). This remark is in line with Arcodia, Grandi and Wälchli (2010), who claim that among coordinate compounds there is a major dichotomy between hyperonymic coordinate compounds also called co-compounds (Wälchli 2005), which express super-ordinate level concepts, and hyponymic coordinate compounds which express subordinate level concepts.

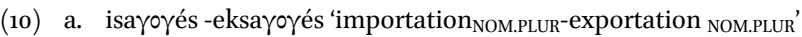

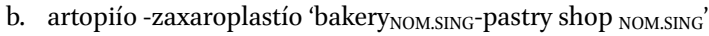

\subsection{Attribution}

Attributive NN combinations allow predicativity as shown in (3a) but not permutation $(2 \mathrm{e})$ nor recursiveness. ${ }^{3}$ Their semantic and syntactic head is situated on the left. Thus, it determines the morphosyntactic properties of the whole

3) Cases such as $\left[\left[\text { katanalotikó }{ }_{\text {ADJ }} \text { proión }{ }_{\mathrm{N}}\right]_{\mathrm{N}^{-}}[\text {maimú }]_{\mathrm{N}}\right]_{\mathrm{N}}$ lit. "[[consuming product $]_{\mathrm{N}^{-}}[$monkey $\left.]_{N}\right]_{N}$ ', thus 'fake consumer product' or [skílos $]_{N^{-}}\left[\text {anixneftís }{ }_{N} \text { narkotikón }{ }_{\text {NPLGEN }}\right]_{N}$ lit. '[dog $]_{N^{-}}$ [detector drug $\left._{\mathrm{NPL}_{-} \mathrm{GEN}}\right]_{\mathrm{N}}$ ', thus 'drug detection dog' found in the my corpus should not in my opinion be treated as instances of recursiveness, insofar as these complex structures cannot be decomposed into two entities of the same type. However, I do not decide this issue here given that it requires more extensive research. 
construction (11a, b). I consider this an indication for their syntactic origin. Nonheads may (11c, d) or may not (11a, b) co-variate in inflection, allowing for the hypothesis that, in contrast with the heads which are inflectable lexemes, nonheads are inflected word forms.

(11) a. tú nómu-plésio 'the GEN.SING law $_{\mathrm{GEN} . S I N G}-$ frame $_{\mathrm{NOM.SING}}$ '

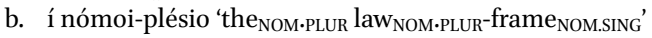

c. tú nómu-plésiu 'the GEN.SING $_{\text {law }}$ laN.SING $_{\text {- }}$ frame $_{\text {GEN.SING' }}$

d. í nómoi-plésia 'the $\mathrm{NOM}_{\mathrm{PLUR}} \mathrm{law}_{\mathrm{NOM} \cdot \mathrm{PLUR}}$-frame $_{\mathrm{NOM} . \mathrm{PLUR}}$ '

The corpus data consultation has shown that hyphen use is not systematic in attributive NN combinations; however a hyphen was used in $60 \%$ of attributive NN combinations of our corpus: $15^{8}$ cases $(7.8 \%)$ were found without hyphen; 122 cases $(6.1 \%)$ included a parallel use of hyphen and quotation marks ("”) (e.g. metoxí- “maimú"lit. 'share-monkey', thus 'share of a nonexistent company'); in 50 cases $(2.5 \%)$ only quotation marks were used (e.g. taksíoi "astrapi” lit. 'journey-lightning', thus 'a very fast journey'); in 3 cases a comma was used (e.g. rolói, maimú lit. 'watch, monkey', thus 'fake watch'). The presence/absence of a hyphen does not seem to affect the syntactic and semantic interpretation of attributive NN combinations.

Among attributive NN combinations there are clear cases which are used as names ${ }^{4}$ for concepts or entities (ánЭropos-aráxni lit. 'man-spider', thus 'spiderman', nómos-plésio lit. 'law-frame', thus 'law framework', pólemos-astrapí lit. 'war-lightning', thus 'blitzkrieg') and others which manifest an expressive meaning in the sense of Potts (2007). In the latter, the non-head, "contributes a dimension of meaning that is separate from its regular descriptive content" (Potts 2007: 156) and offers the speaker's perspective. It also conveys a property of the head, very often through a metaphorical interpretation, in the sense that the head is conceived in terms of the non-head (Benczes 2006). Interestingly, some non-heads convey intensifying meaning and behave as adjectival modifiers (Gavriilidou 1997).

This distinction between attributive NN combinations with or without naming function mirrors a different linguistic behavior of the two subtypes. In attributive NN combinations with naming function such as nómos-plésio 'law framework' (as with the coordinate NN combinations examined before) the non-head cannot be separated from the N1 by the definite determiner (12a), cannot accept a modifier (12b), nor can be split by parenthetical expressions

4) The naming function of NN combinations can be traced with the use of a verb like call (Kleiber 1984). NN combinations with naming function are expected to be natural in phrases such as $A N 1$ which $x$ is called NiN2. 
(12c). The co-variation in inflection (11c) is more frequently attested in attributive $\mathrm{NN}$ combinations with a naming function than in $\mathrm{NN}$ combinations without a naming function. Finally, the use of the hyphen is systematic. These remarks seem to validate Rainer and Varela's (1992) claim that global pluralization or opacity to syntactic rules in A + N constructions in Spanish should be viewed as consequences of the naming function of these structures.

(12) a. *o nómos to plésio

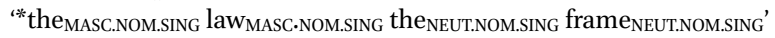

b. *o nómos néo plésio

"*the ${ }_{\text {MASC.NOM.SING }}$ law MASC.NOM.SING new NEUT.NOM.SING frame $_{\text {NEUT.NOM.SING' }}$

c. *o nómos -ópos ksérete- plésio

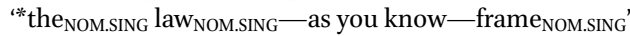

On the other hand, attributive NN combinations without naming function are more easily accepted when the order between $\mathrm{N}_{1}$ and $\mathrm{N}_{2}$ is reversed (13a) (below), especially when accompanied by a specific intonation at the oral level. The non-heads can be modified by maximality modifiers such as endelos 'completely', like scalar adjectives do (13b). As claimed by a number of researchers (Gavriilidou 1997; 2001; Scalise, Bisetto \& Guevara 2005), non-heads like the ones studied here display a functional similarity with adjectival modifiers whose role is to specify an attribute of the head. Finally, as shown in (13c) they do not prefer co-variation in inflection.

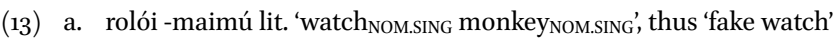
vs. maimú rolói lit. 'monkey NOM.SING $_{\text {watch }}$ NOM.SING', thus 'fake watch'
b. To rolói tu íne endelós maimú lit. 'the NOM.SING $_{\text {watch }}$ NOM.SING his is totally monkeyNOM.SING', thus 'his watch is completely fake'
c. rolója-maimú lit. 'watch NOM.PLUR $_{\text {maimú }}$ NOM.SING' $^{\prime}$

Frequent non heads entering a metaphorical or intensifying relation are for

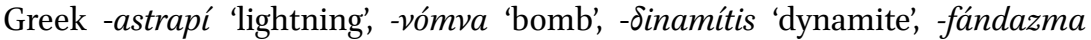
'ghost', -karmanióla, -katapéltis, -keravnós lightning', -maimú 'monkey', -mamú $\vartheta$

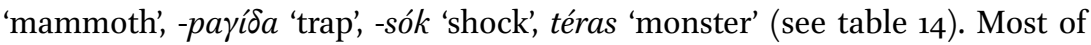
these are calques, ${ }^{5}$ mainly from French (-astrapi 'lightning' in taksioi-astrapi < Fr. voyage éclair 'very fast and sudden trip') and English (-klidi 'key' in erótisi$k$ klioi < Eng. 'key question'), while others are lexical loans (-vómva 'bomb', -sok

\footnotetext{
5) Anastassiadis-Symeonidis (1986) claims that the pattern of NN combinations is calqued from French and American English. She also states that the extension of use of this pattern in Modern Greek is facilitated by the standard word order of predicates and a pre-existing pattern such as mési daxtilioi lit. 'waist ring', thus 'small waist'.
} 
'shock') which became productive in N2 position and gave birth to a number of hybrid NN combinations. ${ }^{6}$

\begin{tabular}{|c|c|c|}
\hline (14) Noun & Lit. meaning & Example \\
\hline -astrapí & 'lightning' & taksíঠi-astrapí 'very fast and sudden trip' \\
\hline -vómva & 'bomb' & apokálipsi-vómva 'groundbreaking disclosure' \\
\hline - ¿inamítis & 'dynamite’ & nomosxéঠio-ঠinamítis 'groundbreaking law framework' \\
\hline -fándazma & 'ghost' & etería-fándasma 'non-existing company' \\
\hline -katapéltis & 'catapult' & epistolí-katapéltis 'a groundbreaking letter' \\
\hline -keravnós & 'lightning' & íoisi-keravnós 'very sudden and unexpected news' \\
\hline -kliði & 'key' & erótisi-kliði ‘key question’ \\
\hline -mamú $\theta$ & 'mammoth' & érevna-mamú $\theta$ 'monstrous research' \\
\hline -paүída & 'trap' & 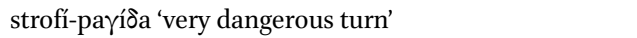 \\
\hline -sók & 'shock' & íঠisi-sók 'shocking news' \\
\hline -téras & 'monster' & rrafiokratía-téras 'monstrous bureaucracy' \\
\hline -fotjá & 'fire' & dílosi-fotjá 'very hot announcement' \\
\hline
\end{tabular}

These N2 exist as independent words but have acquired a specific more abstract meaning when part of a NN combination as specified in the right column in (14). They are used in combination with Niand form with them attributive NN combinations with a shared meaning component. In some cases the semantic explanation for the new abstract meaning (intensifying or not) is relatively transparent, as for instance in taksídi-astrapí lit. 'trip-lightning', thus 'very fast and sudden trip', which could be interpreted as 'a trip which is fast as lightning.? In other cases the semantic relation is more opaque as for instance, in the Greek word maimú 'monkey' which has developed the meaning 'fake' or 'imitation' as illustrated in (15).

(15) -maimú 'monkey' rolói-maimú lit. 'watch-monkey', thus 'a fake watch', etería-maimú lit. 'company-monkey', thus 'a non-existing company', taksí-maimú lit. 'cab-monkey', thus 'a taxi without the legal license or taximeter'

Booij (2010a: 57) referring to similar words such as bliksem 'lightning' in constructions like bliksem-actie lit. 'lightning action', thus 'fast action', notes that "such words are sometimes called affixoids because they have become similar to affixes in having acquired an abstract meaning when embedded in compounds." However, in contrast with affixes, they correspond to lexemes and they can be found as unbound words as well. In Gavriilidou (2001) N2 like the ones in (12) were treated as cases of grammaticalization. Gavriilidou (2013) has

\footnotetext{
6) By hybrid $\mathrm{NN}$ combinations we refer to $\mathrm{NN}$ combinations which consist of a native head and a borrowed word as modifier (e.g. ídisi-sók lit. 'news-shock', thus 'shocking news'). The hybrid NN combinations preserve the Greek word order with the modifier noun at the right.

7) Equivalent examples from Dutch include: bliksem-actie lit. 'lightning action', thus 'fast action', bliksem-bezoek lit. 'lightning visit', 'fast visit' (Booij: 2010a: 57).
} 
further elaborated on the idea of a possible grammaticalization of attributive N2, delimitating this hypothesis only for intensifying N2. Based on Paradis (2008), she explains the functional similarity of intensifying N2 with adjectival modifiers as a matter of different Gestalt construals, different configurations but the same content structures. In other words, cases like -vómva 'bomb', - -inamitis 'dynamite', -fotiá 'fire' are construed as adjectives, foregrounding the configurational structure of DEGREE and backgrounding the content structures (literal meaning) of the words. Several factors typical of grammaticalization take place in these examples: (a) there is divergence from the initial meaning of nouns like -vómva 'bomb', -dinamítis 'dynamite', -fotiá 'fire', and specification in meaning (Hopper 1991); (b) The shift to intensifying meaning occurred in a very restricted context, specifically when these words are found in NN combinations; (c) In this context, the nouns were re-analyzed as adjectives and the intensifying meaning was conventionalized and became productive; (d) However, the initial meaning of these nouns is available (persistence) in unbounded uses; (e) the new meaning is more abstract, speaker-based, strongly grounded in the situation and consequently more subjective (Paradis 2008).

Let us notice that first constituents in attributive combinations may also develop productive patterns. In Greek, the word rinéka-vuleftís 'woman deputy' created when the first woman deputy was elected back in the $50^{\circ}$ 's functioned as a model of a number of $\mathrm{NN}$ combinations where the $\mathrm{N} 1$ yinéka- 'woman' marks the feminine gender in nouns of professions which do not have a morphologically distinct form for the feminine (16a) or in nouns having a morphologically distinct feminine form which carry an ambiguous or pejorative meaning (16b):

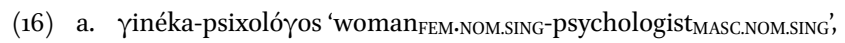

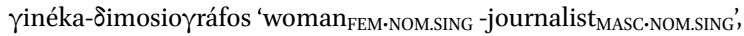

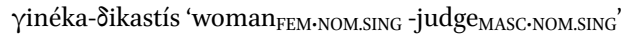

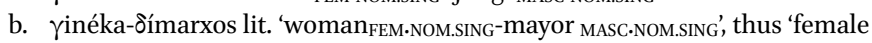
mayor' vs. סimarxína 'female mayor or the wife of mayor'

\subsection{Complementation 8}

NN subordinate sequences illustrated in (17) have their syntactic and semantic head on the left. The head determines the morphosyntactic properties of the whole construction. As can be seen, they are not hyphenated.

8) I borrowed from Noailly (1990) the term complementation (complémentation) to name this category. 


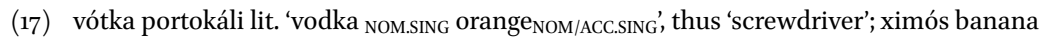
lit. 'juice ${ }_{\text {NOM.SING }}$ banana $_{\text {NOM/ACC.SING', thus 'banana juice'; ximós ananas }}{ }^{9}$

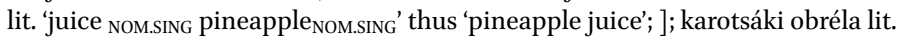

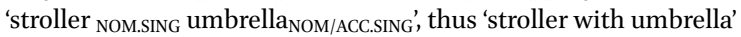

On the exception of ximós ananas lit. 'juice NOM.SING pineapple NOM.SING' above, where $\mathrm{N}_{2}$ is morphologically marked for nominative case, all other $\mathrm{N}_{2}$ in (17) are ambiguous for case, given that in the specific examples the form of nominative and accusative coincide. Consequently, the question that is raised is whether the N2 which are ambiguous for case are processed by Greek speakers as being in the nominative or in accusative.

In order to answer this question, let us first mention that $\mathrm{NN}$ combinations like the ones in (17) do not pass the criterion of predicativity as exemplified earlier in (3b). This statement allows us to claim that the non-heads do not convey a property of the head but rather some kind of classifying prepositional relation of the type N1 FROM/MADE OF N2 (e.g ximós banána 'banana juice'), $\mathrm{N}_{1}$ WITH N2 (e.g. vótka portokáli 'screwdriver'), $\mathrm{N}_{1} \mathrm{IN} \mathrm{N} 2$ (e.g. payotó kípelo 'ice cream cup'), N1 FOR N2 (vási makijáz lit. 'base make up', thus 'make up base'). Thus, NN combinations belonging to complementation seem to have a classifying function. In other words, the relation that links $\mathrm{N}_{1}$ and N2 determines, to a large extent, the contrast that is relevant for the compound: a yranita fráula lit. 'popsicle strawberry', thus 'strawberry popsicle' is a kind of popsicle which contrasts with other kinds of popsicles (e.g. rranita lemóni lit. 'popsicle lemon', thus 'lemon gcle', $\gamma$ raníta pepóni lit. 'popsicle melon', thus 'melon popsicle', etc.) exactly as sáltsa manitárja 'lit. sauce mushrooms' contrasts with other sauces (e.g. sáltsa Jamáskino lit. 'sauce prune', thus 'prune sauce'). According to Gagné, Spalding \& Corrie (2005: 204) "The relation that is used to link the constituents of a compound heavily influences the meaning of the compound".

If the prepositional relation hypothesis between $\mathrm{N}_{1}$ and $\mathrm{N}_{2}$ in the examples in (17) is valid, then we would expect N2 to be in the accusative, inasmuch as in Greek the accusative is the default case for prepositional complements. The prepositional relation hypothesis and the prediction about the accusative case of $\mathrm{N} 2$ seem to be supported by the fact that complementation NN combinations systematically co-exist with combinations bearing before N2 prepositions such as ja 'for', apo 'from', me 'with', se 'in', which assign accusative case (18a) to the nouns they govern. When complementation $\mathrm{NN}$ combinations are linked with the relation $\mathrm{N}_{1}$ FROM/MADE OF N2, they coexist, not only with combinations bearing a preposition before $\mathrm{N} 2$, but also with subordinate morphological compounds or with structures where $\mathrm{N}_{2}$ has a genitive marker (18b).

9) Example found in http://www.pepsico-ivi.gr/versions/gre/page.aspx?itemID=SPG7. 
(18) a. sáltsa manitárja / sáltsa me manitárja ${ }^{10}$

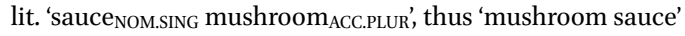

/ Sauce NOM.SING with mushroom ACC.PLUR'

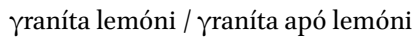

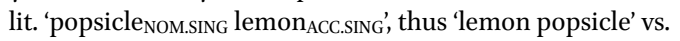

lit. 'popsicle NOM.SING $_{\text {from lemon }}$ ACC.SING' $^{\prime}$

b. ximós domáta / ximós domáta-s / ximós apó domáta/domatoximós

lit. 'juice ${ }_{\text {NOM.SING }}$ tomato $_{\text {ACC.SING', thus 'tomato juice'/'juice }}{ }_{\text {NOM.SING }}$

tomato $_{\text {GEN.SING' }}$ ' 'juice NOM.SING $_{\text {from }}$ tomato $_{\text {ACC.SING' }}$ / 'tomato juice'

Let us mention here that the parallel structures with prepositions can account for the fact that $\mathrm{N} 2$ can be pluralized independently of the head as in the exam-

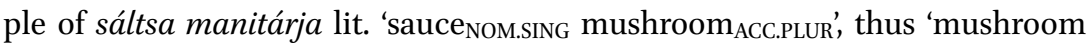
sauce' and also provide indications that these units are phrasal. Another indication of the phrasal nature of these combinations is the systematic absence of the hyphen.

To summarize this section, there are strong arguments that N2 in complementation NN combinations are in accusative case. Although, then, how can we account for the example of ximós ananas lit. 'juice Nom.sing pineapple $_{\text {NOM.SING' }}$ ' where $\mathrm{N} 2$ is in morphologically marked nominative case?

I claim that the structures with prepositions are older in Greek, while complementation $\mathrm{NN}$ combinations, where the modifiers follow directly the head without a preposition, are a relatively modern pattern which seems to be calqued from English but is adapted to Greek word order; the introduction of this pattern in Greek is probably facilitated by native structures with nomi-

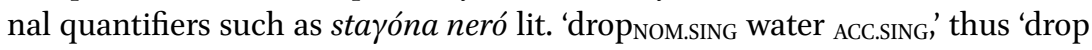
of water', stíva xartjá lit. 'pile NOM.SING paper ACC.PLUR', 'a pile of papers' which have a similar surface structure. In complementation NN combinations, N2 in accusative are then re-analyzed by Greek speakers as being in the nominative. This re-analysis was motivated by the fact that often the nominative and accusative morphological form coincides for a lot of nouns and also by analogy with the other two classes of $\mathrm{NN}$ combinations (the coordinate and the attributive ones) where $\mathrm{N}_{1}$ and $\mathrm{N}_{2}$ are in the same case. Of course, this claim needs to be investigated with the use of experimental methods which could provide evidence about how Greek speakers process N2 in complementation NN combinations. However this goes beyond the scope of the present paper.

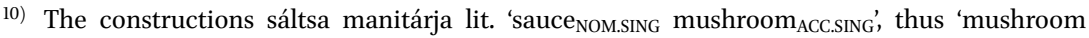
sauce' and sáltsa me manitárja 'sauce ${ }_{\mathrm{NOM} . S I N G}$ with mushroom $_{\mathrm{ACC.SING}}$ ' seem to differ in meaning from sáltsa manitárjón lit. 'sauce ${ }_{\text {NOM.SING }}$ mushroom ${ }_{\text {GEN.SING' }}$. The two first denote a kind of sauce with whole mushroom parts while the latter is a mushroom paste. 
To conclude Section 2: I have provided a detailed analysis of the formal characteristics of Greek NN combinations, demonstrating that there are three different subtypes: attributive, coordinative, and complementation. The goal of the next section is to discuss each subtype in the light of construction morphology.

\section{The Analysis of NN Combinations in the Light of Construction Morphology}

Let us turn now to the remaining questions raised at the beginning of the paper: 2) If we are convinced that there are different subtypes of NN combinations, how are these subtypes accounted for by construction morphology?; 3) Does each subtype receive syntactic or morphological interpretations?; 4) In case we opt for syntactic interpretations, how can we account, on the one hand, for the functional similarities between morphological compounds and NN combinations and, on the other, for the differences in the morphological autonomy of each subtype?; 5) How can we account for the left-headedness in NN combinations in Greek which is considered to have right-head compounding?; 6) How can we account for the fact that some non-heads in NN combinations are projecting while others not?; and finally, 7) how can we account for the specific meaning that certain non-heads acquire when embedded in attributive NN combinations or the affix-like behavior of some heads also embedded in attributive $\mathrm{NN}$ combinations?

In addressing Q2 (question 2) I employ the notion of word construction schema. For Q3 and Q4 I make use of the notion of construction (Booij 2005; 2009; 2010a; 2010b), and for Q6 and Q7, I base my account on the notion of constructional idiom and hierarchical lexicon (Booij 2005; 2009; 2010a; 2010b). Q3, $\mathrm{Q}_{4}$, and $\mathrm{Q}_{5}$ are addressed together.

Let me begin with Q2. Construction morphology assumes the co-existence of abstract patterns (schemas) and complex words instantiating these schemas listed in the lexicon. These schemas, as covered in Section 1, express predictable properties of existing complex words, indicate how new ones can be coined, and give structure to the lexicon (Booij 2010a: 4). The abstract schema in (19) is needed to represent $\mathrm{NN}$ combinations in Greek:

(19) $\left[[\mathrm{N}]_{\mathrm{Nk}}[\mathrm{N}]_{\mathrm{Ni}}\right]_{\mathrm{NNj}} \leftrightarrow\left[\mathrm{SEM}_{\mathrm{k}} \text { with relation } \mathrm{R} \text { to } \mathrm{SEM}_{\mathrm{i}}\right]_{\mathrm{j}}$

The lower-case variables $i, j, k$ stand for the lexical indexes on the PHON, SYN and SEM properties of words. All NN combinations created in Greek are individual instantiations of the construction in (19). However this general pattern does not yet provide information about the nature of the semantic relation $\mathrm{R}$ in the three subtypes of NN combinations. Hence we need to elaborate schemas 
(20), (21), and (22) to account for coordinate, attributive and complementation NN combinations respectively.

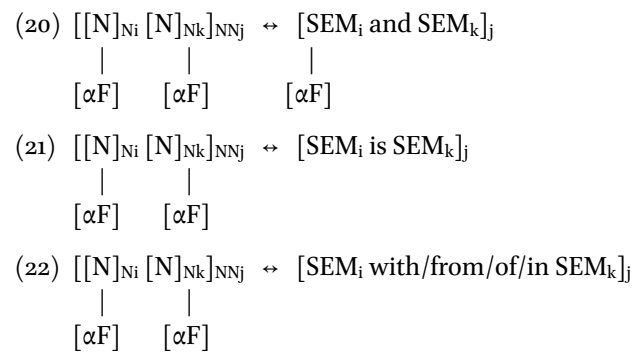

In Schemas (20), (21), and (22), $[\alpha \mathrm{F}]$ stands for the set of relevant subclass features. Template (20) specifies that $\mathrm{N}_{\mathrm{i}}$ is the syntactic head of the NN combination, that the syntactic category of the syntactic head is identical to that of the whole $\mathrm{NN}$ combination, and that all the $\mathrm{N}$-nodes are also identical with respect to properties such as gender or number. It specifies as well that $\mathrm{N}_{\mathrm{i}}$ and $\mathrm{N}_{\mathrm{k}}$ are both semantic heads: a coordinate $\mathrm{NN}$ combination denotes a certain $\mathrm{N}_{\mathrm{j}}$ which is $\mathrm{N}_{\mathrm{k}}$ and $\mathrm{N}_{\mathrm{i}}$.

Template (21) expresses that $\mathrm{N}_{\mathrm{i}}$ is the head on the $\mathrm{NN}$ construction and that it is not only the syntactic category of the head that is identical to that of the whole NN combination, but the two N-nodes are also identical with respect to properties such as gender. Furthermore, it specifies that the head is not only the formal head but also the semantic head: an attributive $\mathrm{NN}$ combination denotes a certain $N_{i}$ which is a $N_{k}$ and not a certain $N_{k}$.

Finally, Template (22) like template (21) expresses that $\mathrm{N}_{\mathrm{i}}$ is the head on the $\mathrm{NN}$ construction and that it is not only the syntactic category of the head that is identical to that of the whole $\mathrm{NN}$ combination, but the two $\mathrm{N}$-nodes are also identical with respect to properties such as gender. It further specifies that the head is not only the formal head but also a semantic head: a complementation $\mathrm{NN}$ combination denotes a certain $\mathrm{N}_{\mathrm{i}}$ which is with/from/of $\mathrm{N}_{\mathrm{k}}$ and not a $\mathrm{N}_{\mathrm{k}}$.

In sub-schemas(20), (21), and (22), the nature of $\mathrm{R}$ is specified and determined for each specific NN combination on the basis of the meaning of the NN combination constituents and encyclopedic and contextual knowledge (Booij 2010a: 17). Moreover, these abstract schemas provide information both for the morphophonological as well as for the general semantic relation between the constituents of NN combinations. All these sub-schemas should be dominated by the general schema (19) which accounts for all NN combinations (see figure 2). A strong advantage of this approach to $\mathrm{NN}$ combination formation is that generalizations about the three sub-types of NN combinations can be expressed in a straightforward way. 
Another property that distinguishes subsets of NN combinations is whether the head constituent and the non-head constituent can be constructed themselves. Corpus data have shown that this phenomenon is not frequent in $\mathrm{NN}$ combinations. It is possible mainly in the case of attributive NN combinations as illustrated in (23a, b, c, d):

(23) a. $\left[\left[[\text { kréma }]_{\mathrm{N}}[\text { iméras }]_{\mathrm{NGEN}}\right]_{\mathrm{Ni}}\left[\left[[\text { vási }]_{\mathrm{N}}[\text { makijáz }]_{\mathrm{NGEN}}\right]_{\mathrm{Nk}}\right]_{\mathrm{NNj}}\right.$ lit. 'cream day-base make up', thus 'day cream-make-up base'

b. $\left.\quad[\text { skílos }]_{\mathrm{Ni}^{-}}\left[\text {anixneftís }_{\mathrm{N}} \text { narkotikón }{ }_{\mathrm{NPLGEN}}\right]_{\mathrm{Nk}}\right]_{\mathrm{NNj}}$ lit. ' $[\operatorname{dog}]_{\mathrm{N}}-\left[\text { detector }{ }_{\mathrm{N}} \operatorname{drug}_{\mathrm{NPL}_{-} \mathrm{GEN}}\right]_{\mathrm{N}}$ ', thus 'drug detection dog'

c. [[katanalotikó ADJ $\left.\left._{\text {proión }}\right]_{\mathrm{Ni}}-[\text { maimú }]_{\mathrm{Nk}}\right]_{\mathrm{NNj}}$ lit. '[[consuming product $\left.]_{\mathrm{N}^{-}}[\text {monkey }]_{\mathrm{N}}\right]_{\mathrm{N}}$, thus 'fake consumer product'

d. $\left[[\text { póli }]_{\mathrm{Ni}}\left[[\theta \text { riskeftikó }]_{\mathrm{A}}[\text { kéndro }]_{\mathrm{N}}\right]_{\mathrm{Nk}}\right]_{\mathrm{NNj}}$ lit. 'city-religious centre', thus 'religious centre city'

Thus we get NN combination structures like the following which would be inserted under the schema (21) in the hierarchical representation of NN combinations (see figure 2).

(24) a. $\left[[[\mathrm{N}][\mathrm{NGEN}]]_{\mathrm{Ni}}[[\mathrm{N}][\mathrm{NGEN}]]_{\mathrm{Nk}}\right]_{\mathrm{NNj}}$

b. $\left[[\mathrm{N}]_{\mathrm{Ni}}[[\mathrm{N}][\mathrm{NGEN}]]_{\mathrm{Nk}}\right]_{\mathrm{NNj}}$

c. $\left[[[\mathrm{A}][\mathrm{N}]]_{\mathrm{Ni}}[\mathrm{N}]_{\mathrm{Nk}}\right]_{\mathrm{NNj}}$

d. $\left[[\mathrm{N}]_{\mathrm{Ni}}[[\mathrm{A}][\mathrm{N}]]_{\mathrm{Nk}}\right]_{\mathrm{NNj}}$

Let us focus now on the degree variations in the morphological autonomy of the three different classes of NN combinations. As demonstrated in sections 2.2, 2.3 and 2.4 above, it is certain that NN combinations are not compounds (in the sense of morphological words) because: i) coordinate combinations require agreement between the two or more constituents with respect to gender, number and case imposed by the first constituent. According to the principle of Lexical Integrity, the syntactic rule of agreement cannot affect parts of words, thus coordinate combinations are not compounds; ii) attributive and complementation combinations, on the other hand, are left-headed while morphological compounds in Greek are right-headed (Ralli 2007; 2009), and hence, these NN sequences cannot be seen as morphological compounds in Greek; iii) complementation NN combinations in addition co-exist with parallel constructions displaying a preposition between $\mathrm{N}_{1}$ and N2.

Additionally, coordinate, attributive and complementation NN combinations contrast with those of Greek coordinate, attributive, and subordinative morphological compounds such as: pandelonofousta lit. 'pants and skirt', vatraxan Эropos 'frogman', spanakopita 'spinach pie', which have structure (25a, b, c).

(25) a. Coordinate syntactic combinations:

$\left[\mathrm{N}^{0} \mathrm{~N}^{0}\right]_{\mathrm{N}}{ }^{0}$ e.g. $\left[[\text { arxitéktonas }]_{\mathrm{N}}{ }^{0}[\text { arxeoló } \gamma o s]_{\mathrm{N}}{ }^{0}\right]_{\mathrm{N}}{ }^{0}$

Coordinate morphological compounds:

$[\text { stem word }]_{\mathrm{N}}$ e.g [pandelon $\left.]_{\text {stemó }}[\text { fusta }]_{\text {word }}\right]_{\mathrm{N}}$ 
b. Attributive syntactic combinations:

$\left[\mathrm{N}^{0} \mathrm{~N}^{0}\right]_{\mathrm{N}}{ }^{0}$ e.g. $\left[[\text { nómos }]_{\mathrm{N}}{ }^{0}[\text { plésio }]_{\mathrm{N}}{ }^{0}\right]_{\mathrm{N}}$

Attributive morphological compounds:

$[\text { stem word }]_{\mathrm{N}}$ e.g $\left.[\text { vatrax }]_{\mathrm{stem}}[\text { ánӨropos }]_{\mathrm{word}}\right]_{\mathrm{N}}$

c. Complementation syntactic combinations:

$\left[\mathrm{N}^{0} \mathrm{~N}^{0}\right]_{\mathrm{N}}^{0}$ e.g. $\left[[\text { ximós }]_{\mathrm{N}}{ }^{0}\left[\text { portokáli } \mathrm{ACC}_{A C \mathrm{~N}}\right]_{\mathrm{N}}\right]_{\mathrm{N}}{ }^{0}$

Complementation morphological compounds:

$[\text { stem word }]_{\mathrm{N}}$ e.g $\left.[\text { spanak }]_{\text {stemó }}[\text { pita }]_{\text {word }}\right]_{\mathrm{N}}$

Coordinate, attributive, and subordinate morphological $\mathrm{N}+\mathrm{N}$ compounds in Greek differ from NN constructions belonging to the class of coordination, attribution, and complementation: in the former, the first constituent is a stem, followed by a linking element $-o-$, and the compound as a whole forms one phonological word (Ralli 2007; 2009). Furthermore, they are dominated by one $\mathrm{X}^{0}$-node only and are subject to rightward headedness as seen above while in $\mathrm{NN}$ combinations the head is situated at the right because of their syntactic origin.

However, there is a functional similarity between, on the one hand, coordinate, attributive, and complementation sequences which have a syntactic origin as showed above and, on the other, morphological compounds as it is deduced by the comparison between compounds and NN combinations in (26a, b, c). Like morphological compounds, some NN combinations in Greek behave as names:

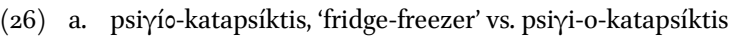

b. ánӨropos-aráxni 'lit. man-spider, spiderman' vs. vatrax-ánӨropos ${ }^{11}$ 'frogman'

c. ximós domáta 'lit. Juice tomato, tomato juice' vs. domat-o-ximós 'tomato juice'

Both the syntactically created psizio-katapsiktis 'fridge-freezer' or ánঐroposaráxni 'lit. man-spider, spiderman' and their morphologically created coun-

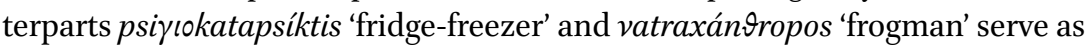
denominations.

Consequently, given that NN combinations like the ones in $(26 \mathrm{a}-\mathrm{c})$ are conventional names for entities or concepts, "they need to be listed in the lexicon, even though they are formed according to non-morphological, that is syntactic schemas" (Booij 2010a:190). In fact, "there is no strict boundary between syntactic and lexical constructs: syntax permeates the lexicon because syntactic units can be lexical" (Booij 2010a: 191). On the other hand, what is considered lexicalized and thus attributed to the lexicon has to be carefully distinguished from what is seen as the result of a morphological operation (Gaeta \& Ricca 2009:

11) According to Ralli (2009), the linking element in Greek compounding is the vowel /o/ which is a semantically empty element. This element "does not surface when the second constituent begins with a vowel" (Ralli 2009: 455). 
38) even though "complex words, i.e. the outputs of morphological operations, can be listed in the lexicon" (Booij 2010:3).

The framework of Construction Morphology provides the theoretical tools to do justice to both the phrasal and lexical nature of NN combinations. More specifically by using the notion of construction we are able to treat adequately both morphological and syntactic word combinations that function as terms and account for their differences or similarities. Thus, following Booij (2010a), like $\mathrm{A}+\mathrm{N}$ phrases with naming function in Dutch, $\mathrm{NN}$ combinations with naming function in Greek can be seen as constructions, put differently pairs of form and meaning, interpreted by a schema such as $\left[\mathrm{N}^{0} \mathrm{~N}_{\mathrm{j}}{ }_{\mathrm{j}}\right]_{\mathrm{k}} \leftrightarrow$ [NAME for $\mathrm{SEM}_{\mathrm{i}}$ with some relation $\mathrm{R}$ to $\left.\mathrm{SEM}_{\mathrm{j}}\right]_{\mathrm{k}}$ in the grammar of Greek. The naming interpretation of these constructional schemas is specified to the right of the double arrow, which stands for the correspondence between form and meaning. More specifically, complementation NN combinations must be seen as phrases with a special syntax in which determiners and prepositions are omitted (Booij 2010a: 175). The meaning contribution of these constructions is that they are used for denominative reasons. It is the naming function and not a possible morphological origin that entails non-projecting non-heads in NN combinations with naming use, as shown in sections 2.2 and 2.3, and can account for differences in the morphological autonomy of them. The naming function creates a tighter relation between the constituents of NN combinations, which, in turn, makes these combinations behave in a more compound-like manner. And of course this compound-like behavior by no means suggests a morphological origin of NN combinations. Hence, attributive NN combinations with a naming use, as well as coordinate and complementation NN combinations, all have the tendency to behave as morphological objects. Put on a "gradient of expression types from synthetic morphological expressions to standard syntactic phrases" (Booij 2010a: 175), these combinations would be closer to the morphological expressions.

We are now in a position to provide an answer to Q5 and Q6. The projecting non-heads in attributive combinations - like the ones in (15) — are possible because that specific group does not share a naming function with the other members of attributive NN class. The absence of naming use does not create a tight relation between $\mathrm{N}_{1}$ and $\mathrm{N}_{2}$, thus $\mathrm{N}_{2}$ can accept a modification, order reversion, or inflectional variation. Mapped on the above-mentioned gradient these combinations would be closer to standard syntactic phrases. It is worth mentioning that I assumed attributive NN combinations to demonstrate more often expressive than denominative function and this assumption was validated by corpus data. ${ }^{12}$

12) $93 \%$ of attributive NN combinations in the Greek corpus displayed expressive meaning. 
In construction morphology, such cases of non-heads can be represented by specifying them in constructional idioms like the ones in (27), in other words "morphological or syntactic schemas, in which one or more positions are lexically fixed, whereas other positions are open slots represented by variables" (Booij 2010b: 96).

(27) Greeknouns

\begin{tabular}{|c|c|c|}
\hline -astrapí & 'lightning' & {$\left[[\mathrm{N}]_{\mathrm{i}}[\text { astrapí }] \mathrm{N}\right]_{\mathrm{j}} \leftrightarrow\left[\text { very fast and sudden } \mathrm{SEM}_{\mathrm{i}}\right]_{\mathrm{j}}$} \\
\hline -vómva & 'bomb' & $\left[[\mathrm{N}]_{\mathrm{i}}[\text { vómva }] \mathrm{N}\right]_{\mathrm{j}} \leftrightarrow$ [groundbreaking $\left.\mathrm{SEM}_{\mathrm{i}}\right]_{\mathrm{j}}$ \\
\hline -¿inamítis & 'dynamite', & {$\left[[\mathrm{N}]_{\mathrm{i}}[\text { dinamítis }] \mathrm{N}\right]_{\mathrm{j}} \leftrightarrow\left[\text { groundbreaking } \mathrm{SEM}_{\mathrm{i}}\right]_{\mathrm{j}}$} \\
\hline -fándasma & 'ghost', & {$\left[[\mathrm{N}]_{\mathrm{i}}[\text { fándasma }] \mathrm{N}\right]_{\mathrm{j}} \leftrightarrow\left[\text { non existing } \mathrm{SEM}_{\mathrm{i}}\right]_{\mathrm{j}}$} \\
\hline -katapéltis & 'catapult' & {$\left[[\mathrm{N}]_{\mathrm{i}}[\text { katapéltis }] \mathrm{N}\right]_{\mathrm{j}} \leftrightarrow\left[\text { groundbreaking } \mathrm{SEM}_{\mathrm{i}}\right]_{\mathrm{j}}$} \\
\hline -keravnós & 'lightning', & {$\left[[\mathrm{N}]_{\mathrm{i}}[\text { keravnós }] \mathrm{N}\right]_{\mathrm{j}} \leftrightarrow\left[\text { very sudden and unexpected } \mathrm{SEM}_{\mathrm{i}}\right]_{\mathrm{j}}$} \\
\hline -maimú & 'monkey' & {$\left[[\mathrm{N}]_{\mathrm{i}}[\text { maimú }] \mathrm{N}\right]_{\mathrm{j}} \leftrightarrow\left[\text { fake } \mathrm{SEM}_{\mathrm{i}}\right]_{\mathrm{j}}$} \\
\hline -mamú $\theta$ & 'mammoth' & {$\left[[\mathrm{N}]_{\mathrm{i}}[\text { mamú } \theta] \mathrm{N}\right]_{\mathrm{j}} \leftrightarrow\left[\text { very big } \mathrm{SEM}_{\mathrm{i}}\right]_{\mathrm{j}}$} \\
\hline -paríða & 'trap', & {$\left[[\mathrm{N}]_{\mathrm{i}}[\text { pa } \gamma \mathbf{i} \delta \mathrm{a}] \mathrm{N}\right]_{\mathrm{j}} \leftrightarrow\left[\text { very dangerous } \mathrm{SEM}_{\mathrm{i}}\right]_{\mathrm{j}}$} \\
\hline -sók & 'shock', & {$\left[[\mathrm{N}]_{\mathrm{i}}[\text { sók }] \mathrm{N}\right]_{\mathrm{j}} \leftrightarrow\left[\text { very shocking } \mathrm{SEM}_{\mathrm{i}}\right]_{\mathrm{j}}$} \\
\hline -téras & 'monster' & {$\left[[\mathrm{N}]_{\mathrm{i}}[\text { téras }] \mathrm{N}\right]_{\mathrm{j}} \leftrightarrow\left[\text { monstrous } \mathrm{SEM}_{\mathrm{i}}\right]_{\mathrm{j}}$} \\
\hline -fotjá & 'fire' & {$\left[[\mathrm{N}]_{\mathrm{i}}[\text { fotjá }] \mathrm{N}\right]_{\mathrm{j}} \leftrightarrow\left[\text { very hot } \mathrm{SEM}_{\mathrm{i}}\right]_{\mathrm{j}}$} \\
\hline
\end{tabular}

Constructional idioms can be also used to represent the borderline case of yinéka- 'woman' (see section 2.3, examples 16ab), which seems to have lost its lexical meaning and simply indicates the feminine form of professional nouns:

(28) $\left[[\text { үinéka }]_{N}[N]_{i}\right]_{j} \leftrightarrow\left[\text { Feminine of } \mathrm{SEM}_{\mathrm{i}}\right]_{\mathrm{j}}$

Constructional idioms in (27) and (28) express that speakers are able to make sub-generalizations about subsets of NN combinations, and thus create new $\mathrm{NN}$ combinations in which the lexicalized meaning of certain $\mathrm{N}_{2}$ can be used productively (Booij 2010a). Within a hierarchical lexicon, constructional idioms can be seen as sub-schemas or the intermediate patterns between abstract lexical patterns that generalize about the structure of existing compounds and individual compounds (Booij 2009). Put differently, constructional morphology allows us to make generalizations about the subset of attributive NN constructions without naming function, while at the same time representing the common properties of the whole set of NN combinations.

The hierarchical representation with different levels of abstractness and generalizations over subsets of NN combinations is shown in Figure 2. In this representation, the grammar contains a network of relationships between words and schemas. At the first level, the general schema (see template 19) specifies the category of NN combinations in Greek. This schema is instantiated by three sub-schemas one for coordinate (template 20), one for attributive (template 21), and one for complementation NN combinations (template 22). The link between some of the coordinate, attributive, and complementation $\mathrm{NN}$ combinations and the naming function is described at the third level of the 


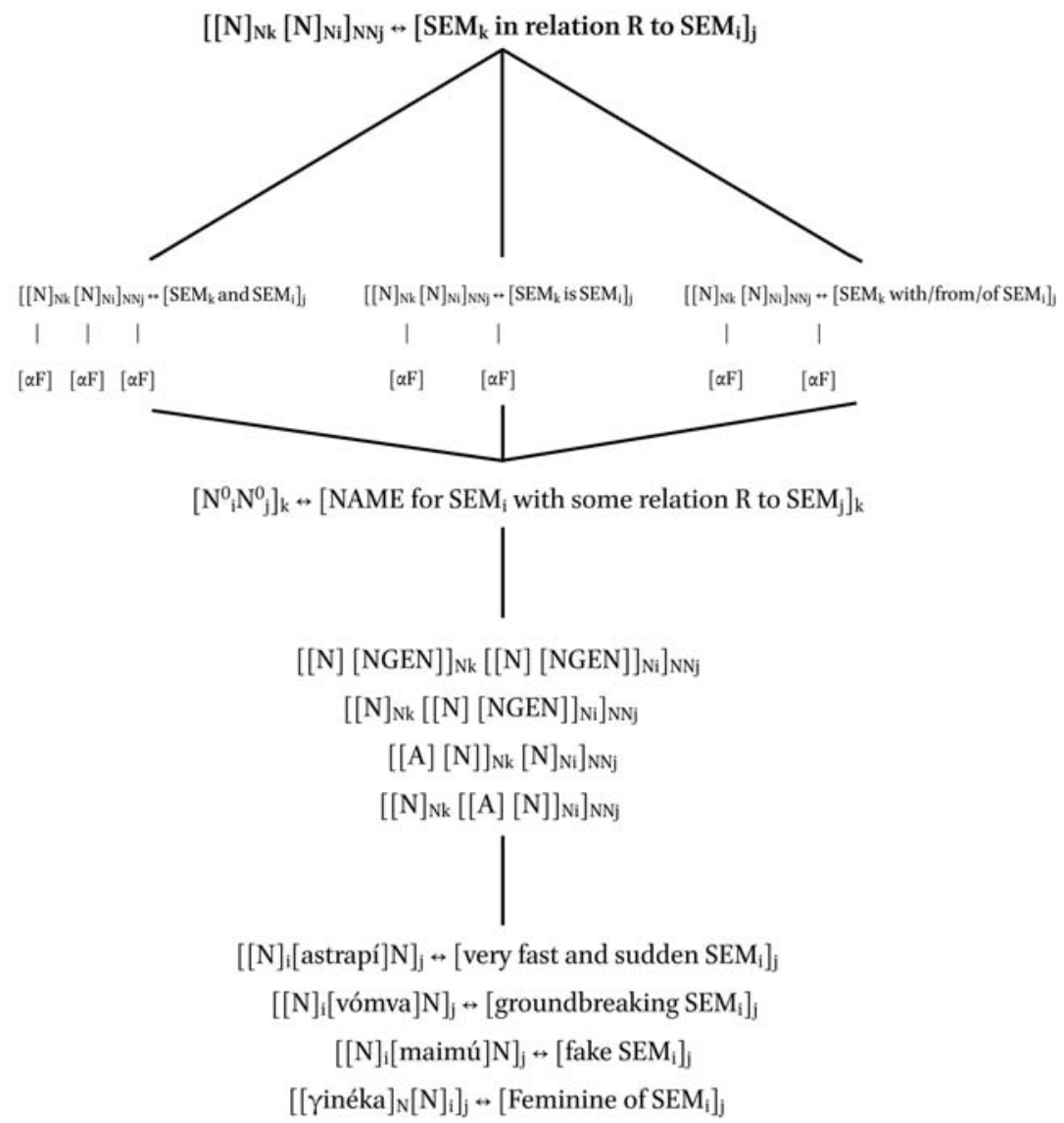

Figure 2. The hierarchical representation of Greek NN combinations in Construction

representation. The possibility of the parts of attributive combinations to be compounds is shown at the fourth level in the hierarchical representation of NN combinations. Finally at the lower level, constructional idioms formally express meaning restrictions of lexical items such as -maimú 'monkey' or -astrapí 'lightning' when embedded in attributive NN combinations. It should be noted that each lower node inherits the properties of its dominating node. Greek speakers become aware of these schemas or sub-schemas on the basis of their use of a number of NN combinations that instantiate this pattern (Booij 2005). However, "the existence of abstract productive schemas for complex words does not mean that these words are no longer stored in the lexicon" (Booij 2005: 125). 
What is seen in Figure 2 is the architecture of the grammar of NN combinations, the role of lexical units of various degrees of abstraction and the relation of the grammar of NN combinations to facts of language use (for instance frequency as it can be seen from the lower level of representation in Figure 2). Generalizations about subsets of NN combinations are expressed in the hierarchically structured lexicon in Figure 2, by assuming intermediate levels of abstraction between the most general template (level one) and the individual existing NN combinations (level four). Thus it becomes possible to provide generalizations about subsets of NN combinations, while at the same time we express the common properties of all NN combinations. What is important, is the fact that using the theoretical tools of Construction Morphology we both specify the existing set on NN combinations in Greek, and we show that they have been formed according to a regular and productive schema that may lead to novel NN formation as well.

In sum, using as theoretical tools the notion of construction as a pairing of form and meaning, building the grammar of $\mathrm{NN}$ combinations as a network of constructions of various degrees of abstractness, and assuming paradigmatic relations between constructions, I have attempted to cope with the relation between form and function in NN combinations in Greek and to do justice to borderline cases of $\mathrm{NN}$ combinations between morphology and syntax. I conclude that all types of $\mathrm{NN}$ combinations are visible to syntactic operations. NN combinations with a naming use exhibit a more compound-like behavior than NN combinations without a naming function. These similarities and differences between phrases, compounds and various types of NN combinations can be accounted for by theoretical tools of construction morphology such as constructional idioms, hierarchical lexicon, and word formation templates.

\section{Summary}

In this paper I focused on the study of NN combinations in Greek in the light of construction morphology. I used a tripartite classification of NN combinations which was based on the grammatical relation between the constituents of such combinations. I concluded that although all three types of NN combinations (coordinate, attributive, and complementation $\mathrm{NN}$ combinations) are visible to syntactic operations, they exhibit, however, various degrees of tightness which are due to whether they exhibit a naming function or not. The similarities and differences between such combinations and morphological compounds were accounted for by using the notions of construction and constructional idiom within the framework of construction morphology. 


\section{References}

Anastassiadis-Symeonidis, Anna. 1986. Neology in Modern Greek Koine [in Greek]. Thessaloniki: Epistimoniki Epetirida Filosofikis Sxolis.

Arcodia, Giorgio Francesco, Nicola Grandi, and Bernhard Wälchli. 2010. Coordination in compounding. In Sergio Scalise \& Irene Vogel (eds.), Cross-Disciplinary Issues in Compounding, 177-198. Amsterdam: John Benjamins Publishing Co.

Aronoff, Mark. 1976. Word formation in Generative Grammar. Cambridge, Massachusetts: MIT Press.

Bauer, Laurie. 2005. The borderline between derivation and compounding. In Wolfgang U. Dressler, Dieter Kastovsky, Oskar E. Pfeiffer and Franz Rainer (eds.), Morphology and its demarcations, 97-108. Amsterdam: John Benjamins Publishing Co.

Bisetto, Antonietta. 2010. Recursiveness and Italian compounds. SKASE Journal of Theoretical Linguistics [online] 7(1). Accessed 14 October 2011. http://www.skase.sk/Volumes/JTL15/pdf_doc/ 02.pdf

Booij, Geert. 2005. Compounding and derivation: evidence for construction morphology. In Wolfgang U. Dressler, Dieter Kastovsky, Oskar E. Pfeiffer and Franz Rainer (eds.), Morphology and its demarcations, 109-132. Amsterdam: John Benjamins Publishing Co.

Booij, Geert. 2009. Compounding and construction morphology. In Rochelle Lieber and Pavol Štekauer (eds.), The Oxford Handbook of Compounding, 201-216. Oxford: Oxford University Press.

Booij, Geert. 2010a. Construction Morphology. Oxford: Oxford University Press.

Booij, Geert. 2010b. Compound construction: Schemas or analogy? In Sergio Scalise and Irene Vogel (eds.), Cross-Disciplinary Issues in Compounding, 93-107. Amsterdam: John Benjamins Publishing Co.

Benczes, Réka. 2006. Creative compounding in English. Amsterdam:John Benjamins Publishing Co. Fradin, Bernard. 2003. Nouvelles approches en morphologie. Paris: Presses Universitaires de France.

Fradin, Bernard. 2009. IE, Romance: French. In Rochelle Lieber and Pavol Štekauer (eds.), The Oxford Handbook of Compounding, 417-435. Oxford: Oxford University Press.

Gaeta, Livio and Davide Ricca. 2009. Composita solvantur: Compounds as lexical units or morphological objects? Rivista di Linguistica 21..1, 35-70.

Gagné, Christina L., Thomas L. Spalding and Melissa C. Corrie. 2005. Sentential context and interpretation of familiar open-compounds and novel modifier-noun phrases. Language and Speech 42.2, 203-221.

Gavriilidou, Zoe. 1997. Etude comparée des suites NN en français et en grec. Elaboration d'un lexique bilingue. Lille: Presses Universitaires du Septentrion.

Gavriilidou, Zoe. 2001. Structures Dét N1N2 et Détermination figée. In Xavier Blanco, Pierre-André Buvet and Zoe Gavriilidou (eds.) Détermination et Formalisation, Linguisticae Investigationes: Supplementa 23, 163-177. Amsterdam: John Benjamins Publishing Co.

Gavriilidou, Zoe. 2013. Aspects of intensity in Modern Greek (In Greek). Thessaloniki: Kyriakidis.

Gross, Gaston. 1988. Degré de figement des noms composés. Langages 90, 57-72.

Gross, Maurice. 1986. Grammaire transformationnelle du français 2, Syntaxe du nom. Paris: Cantilène.

Hopper Paul J. 1991. On some Principles of Grammaticalization. In Elizabeth Closs-Traugott and Bernd Heine (eds.), Approaches to Grammaticalization, v.1: 17-35. Amsterdam:John Benjamins Publishing Co.

Kleiber, Georges. 1984. Dénomination et relations dénominatives. Langages 76, 77-94. Larousse, Paris.

Lieber, Rochelle. 2004. Morphology and lexical semantics. Cambridge: Cambridge University Press.

Lieber, Rochelle. 2009. A lexical semantic approach to compounding. In Rochelle Lieber and Pavol Štekauer (eds), The Oxford Handbook of Compounding, 78-104. Oxford: Oxford University Press. 
Nespor, Marina and Angeliki Ralli. 1996. Morphology-Phonology Interface: Stress Domain in Greek Compounds. The Linguistic Review 16, 357-382.

Noailly, Michelle. 1990. Le substantifépithète. Paris: PUF.

Paradis, Carita. 2008. Configurations, construals and change: Expressions of DEGREE. English Language and Linguistics 12, 317-343.

Ralli, Angeliki. 2005. Morphology [in Greek]. Athens: Patakis.

Ralli, Angeliki. 2007. The Composition of Words. A Morphological Cross-linguistic Approach [in Greek]. Athens: Patakis.

Ralli, Angeliki. 2009. IE: Hellenic: Modern Greek. In Rochelle Lieber and Pavol Štekauer (eds), The Oxford Handbook of Compounding, 453-463. Oxford: Oxford University Press.

Ralli, Angeliki. 2010. Compounding versus derivation. In Sergio Scalise and Irene Vogel (eds.), Cross-Disciplinary Issues in Compounding, 57-76. Amsterdam: John Benjamins Publishing Co.

Rainer, Franz and Soledad Varela. 1992. Compounding in Spanish. Rivista di Linguistica 4, 117-142.

Scalise, Sergio. 1984. Generative Morphology. Dordrecht: Foris.

Scalise, Sergio, Antonietta Bisetto, and Emiliano Guevara. 2005. Selection in compounding and dérivation. In Wolfgang U. Dressler, Dieter Kastovsky, Oskar E. Pfeiffer \& Franz Rainer (eds.), Morphology and its demarcations, 133-150. Amsterdam: John Benjamins Publishing Co.

Scalise Sergio and Antionetta Bisetto. (2009). The classification of compounds. In Rochelle Lieber and Pavol Štekauer (eds), The Oxford Handbook of Compounding, 34-53. Oxford: Oxford University Press.

Štekauer, Pavol. 2005. Compounding and affixation: Any difference? In Wolfgang U. Dressler, Dieter Kastovsky, Oskar E. Pfeiffer and Franz Rainer (eds.), Morphology and its demarcations, 151-16o. Amsterdam: John Benjamins Publishing Co.

Ten Hacken, Pius. 200o. Derivation and compounding. Morphology 2000, 349-359.

Potts, Chris. 2007. The expressive dimension. Theoretical Linguistics 33(2), 165-198.

Wälchli, Bernhard. 2005. Co-compounds and Natural Coordination. Oxford: Oxford University Press. 